\title{
The Progression of Client-Vendor Relationships in Offshored Applications Development
}

Article · January 2008

CITATIONS

0

1 author:

\section{Rajesh Mirani}

University of Baltimore

28 PUBLICATIONS 550 CITATIONS

SEE PROFILE
READS

9

Some of the authors of this publication are also working on these related projects:

Project (To be Decided) View project

All content following this page was uploaded by Rajesh Mirani on 07 May 2015. 


\title{
Chapter VII The Progression of Client-Vendor Relationships in Offshored Applications Development
}

\author{
Rajesh Mirani \\ University of Baltimore, USA
}

\begin{abstract}
This chapter presents an evolutionary framework for the establishment and progression of client-vendor relationships in the context of offshored applications development. It is argued that such a relationship typically begins as a cost-reduction exercise, with the client contracting out simple, structured applications to one or more offshore vendors. Over time, the client assigns increasingly complex applications to selected vendors, and cultivates loose, trust-based, network-like relationships with them. As offshored applications continue to evolve and become business-critical, the client may seek to regain control by establishing a command-based hierarchy. This may be achieved through part-or full-ownership of a vendor organization, or by starting a captive offshore subsidiary. Thus, the initial client objective of cost reduction is ultimately displaced by one pertaining to risk control. Pertinent prior research is used to justify the proposed framework. This is followed by a case study that describes how a specialty telecommunications company is pursuing just such an evolutionary path.
\end{abstract}

\section{INTRODUCTION}

Strategic-level managers, such as CEOs, CIOs, and CTOs, have lately been under great pressure to seek out fresh approaches to control infor- mation technology (IT) costs and demonstrate higher returns on technology investments. A recent International Data Corporation (IDC) study on vertical market IT spending concluded that end users worldwide spent $\$ 1.16$ trillion on 
information technology in 2006, and estimated this figure to grow to $\$ 1.48$ trillion by 2010 ( $\mathrm{Lu}$, Koch, Folco, Dillon, Maceska, \& Gibin, 2007). Of this projected statistic, software and services were expected to cost about $62 \%$ (more than $\$ 900$ million), the remainder attributed to hardware costs. One increasingly popular response from decision makers to the high costs of IT has been offshoring; the shift of development, maintenance, operations, or call center work to low-wage offshore locations.

This chapter focuses specifically on offshored applications development, and how its attributes shape the evolution of relationships between clients and vendors. Many organizations have recently intensified efforts to offshore their development work, citing growth strategy, speed to market, and productivity as major reasons, using captive/subsidiary units, independent offshore providers, or hybrid approaches as common business models (The Software \& Information Industry Association, 2006). Assertions in the practitioner literature regarding the relative merits and demerits of these models are often mutually contradictory. Academic research has provided some valuable lessons on the management of IT outsourcing, with advocates of various approaches employing transaction cost economics, resource dependency, strategic choice, stakeholder theory, organizational learning, and institutional theory to propound their arguments and test their assertions (Barringer \& Harrison, 2000). However, these management prescriptions have been neither formulated nor tested in the specific context of offshored applications development. The implicit assumption underlying this omission appears to be that valid arguments for the general IT outsourcing/offshoring context must also apply to applications development, regardless of task attributes. Most theories also embody static views of client-vendor relationships. They advocate either partnerships/alliances, a network-oriented, trust-based perspective (e.g., Oza, Hall, Rainer, \& Grey, 2006; Willcocks \& Choi, 1995), contracts and transactions, a market-oriented, enforcementbased perspective (e.g., Barthélemy \& Quélin, 2006; Richmond \& Seidmann, 1993), or a mix of both (e.g., Koh, Ang, \& Straub, 2004; Sabherwal, 1999). The inherent problem with static perspectives is that they do not acknowledge the potential need for relationships to change and evolve flexibly in dynamic business environments (Tan \& Sia, 2006). Some studies that have explored the evolutionary nature of outsourcing have nonetheless confined themselves to specific, narrow aspects of relationships such as duration (Goo, Kishore, Nam, Rao, \& Song, 2007), discontinuation (Whitten \& Leidner, 2006), and the growth of social relationships within projects (Cata \& Raghavan, 2006). A maturity model delineating the likely stages of growth for client-vendor relationships has been proposed elsewhere (Gottschalk \& Solli-Sæther, 2006). However, its exclusive focus on fulfilled objectives in each stage as pivotal end points for an opportunity-centric transition to the next stage precludes a deeper discussion thatneeds to address imperatives, including potential risks of opting not to undertake each such transition.

This chapter contends that for offshored applications development, the ostensible choices of management approaches represent not only progressive but also imperative stages for the client in the evolution of its relationships with one or more vendors. The process by which clients and vendors coordinate with each other changes dynamically, depending on shared experiences, organizational learning achieved, mutually adjusted expectations, shifting needs, and, significantly, impediments in continuing with past relationship modes. While several alternative evolutionary paths for this relationship may be feasible, each with its own set of antecedents, process dynamics, and consequences, the discussion here makes the case for one likely path. In this path, a given client organization successively evolves through specific offshoring stages, not all necessarily with the same application development vendor. 
Specifically, a client's experimentation with offshoring begins with reduced development costs as the desired goal. Over time, interplay between the intrinsic task characteristics of application development and the unique attributes of offshoring broaden and evolve the client's goals. The risks and compulsions associated with these evolving goals inexorably alter the nature of the client-vendor relationship in distinct stages. The rationale for this path is supported with logical argument, evidence from the published literature, and an original case study for illustration.

\section{STAGES IN OFFSHORED APPLICATIONS DEVELOPMENTS}

Like all buyers and suppliers, offshore vendors and clients essentially interact in one of two ways, transactional/market exchanges or relational exchanges. A transactional exchange is usually a short-term contract, characterized by free-market price mechanisms and the need for enforcement. A relational exchange implies a longer-term relationship with ongoing interactions. Relational options include long-term contracts, networks, and hierarchies. Long-term contracts resemble the short-term variety, except that they address many more contingencies and consequences. Networks emphasize interorganizational trust, association, and solidarity. Hierarchies refer to rather rigid structural relationships based on formal authority and command, usually stemming from ownership of one organization by another.

As mentioned earlier, the published literature has focused almost exclusively on contracts and networks as mutually exclusive types of clientvendor relationships in the offshoring/outsourcing context. This chapter will show that applications development offshoring initiatives usually begin as transactional exchanges but end up in the relational realm. The evolutionary path that clientvendor relationships will tend to follow consists of three stages. In the first stage, a client contracts out some application development to an offshore vendor, with the objective of reduced costs. Success at this experimental stage may result in shortterm contracts being replaced by fewer, long-term ones. Stage two arrives when the changing nature of tasks, together with the relationship attributes, make it difficult for both client and vendor to continue in a purely contractual vein. The need for closer working ties and greater trust brings about a network-like relationship. With the increasing vendor dependence that this engenders, the importance of the client's original cost-reduction objective is gradually displaced by a strong desire to manage vendor risk. Paradoxically, therefore, the very success of a network-style relationship causes the original success criteria to give way to new ones. This ushers in stage three. In a bid to regain tighter vendor oversight and control, the client seeks to establish a structural hierarchy with the vendor. Doing so may be impractical if there are multiple vendors or if a structural relationship is infeasible for other reasons, so one option in the third stage is for the client to establish a new captive offshore subsidiary.

\section{Stage 1: Contracts}

Labor costs constitute the single major source of application development expenses. The abundant availability of qualified software engineers in low wage countries typically drive a client organization's exploratory efforts to seek out an overseas vendor, with the objective of significantly reduced development costs (Matloff, 2004). Preliminary contact with a prospective offshore vendor has the attributes of a highly efficient, classic freemarket exchange. Both parties, unconstrained by prior contact experiences or future relationship expectations, are fully focused on negotiating the current transaction, with a view to maximizing their respective short-term utilities. Such an exchange tends to yield the best possible outcomes for both client and vendor, but only in the presence of perfect information, that is, complete knowl- 
edge about each other's objectives, strengths, and weaknesses.

All information services markets, however, are beset by the presence of information monopoly or asymmetry (Park, 1996), which is the exact opposite of perfect information or complete knowledge. Geographical, cultural, business, and regulatory differences, inherent to the offshoring context, exacerbate this asymmetry (Ramarapu, Parzinger, \& Lado, 1997). The vendor faces a rather limited amount of risk from this asymmetry. Depending on its past experience with other clients, the vendor may or may not possess an understanding of this client's application context or its industry's business processes. The vendor may also have concerns regarding its interactions with the client, or the latter's financial stability. However, the client's lack of familiarity with the vendor's business environment exposes it to many more risks, including shoddy development processes and practices, poor product quality, poor documentation, incomplete or inappropriate solutions, and business process integration issues. The lack of information transparency thus affects the client more severely than the vendor.

The larger and more complex the application, the higher the development risks (Barros, Werner, $\&$ Travassos, 2004). To reduce these risks and minimize the impacts of any detrimental outcomes, therefore, the client organization follows a cautious approach in identifying initial work to send offshore. This implies small applications or components of low complexity, for which specifications can be completely communicated, and whose development process is highly structured. Such applications call for little vendor supervision, and no need for a window into the vendor's internal processes. A transaction-oriented, contractual relationship between client and vendor suffices as the control mechanism, thereby, keeping interorganizational coordination costs incurred by the client to a minimum.

Unpleasant experiences with these initial applications can quickly end the client's experi- mentation with offshored development. On the other hand, successful initiatives not only result in reduced costs, but also heighten the client's awareness of offshoring's potential to sustain or even raise software quality (Khan \& Fitzgerald, 2004). This emboldens the client to outsource more applications to the same vendor or even to new vendors (Benamati \& Rajkumar, 2002). Heightened client awareness, though, is accompanied by the expectation that vendors will put in the effort into acquiring a deeper understanding of its business processes and information needs. In turn, vendors rationalize the extra effort required from these fresh expectations with their own long-term goals of being assigned progressively higher-level work or serving larger markets. Successful outcomes that result from these mutual commitments serve to supplant the client's original objective of reduced costs with the realization that it may be able to reap collaborative synergies with vendors by moving beyond the scope of simple applications into higher-end development (King, 2005). Collaborative efforts on more complex tasks can yield innovative outcomes, including new solutions, new approaches to problems, unique value-added propositions, and ultimately, original sources of competitive advantage for the client (Dyer \& Singh, 1998). Accordingly, the client entrusts more-complex applications to selected vendors, with less structure and more room for creativity and innovation. As enhanced complexity necessitates a closer working relationship, the client may "move to the middle" by replacing several short-term contracts with a handful of long-term contracts (Clemons, Reddi, \& Row, 1993), essentially substituting transactional interactions with fewer relational mechanisms.

However, long-term contracts increase interorganizational coordination costs by placing greater collaborative and enforcement burdens on the client. They also hinder collaborative innovation because both client and vendor may be reluctant to share valuable, firm-specific resources with unfettered, autonomous, distant partners (Goes 
\& Park, 1997). Their mutual independence and freedom of action outside the limited terms of the contract, even a long-term one, causes both organizations to continue to be wary of each other's intentions and actions. Thus, beyond the simplest applications, the continued use of purely contractual arrangements is ineffective because contracts merely replace the traditional in-house project risks with a different set of more perilous vendor risks. Despite initial successes, therefore, the probability of eventual failure remains significantly high (Natovich, 2003).

Ongoing offshoring relationships also bring asset specificity, dependence, measurement difficulty, and uncertainty into play. Asset specificity refers to investments by relationship partners in information or physical assets that have little value outside the context of that specific relationship. With higher application complexity, both vendor and client invest ever more time and energy into understanding each other's unique processes, and increasing asset specificity is inevitable. Asset specificity, and the resultant dependence, give rise to opportunism, the tendency of one partner (usually the vendor) to take advantage of the fact that the other partner has invested too much in the relationship to walk away from it (Lonsdale, 2001). The awareness of such an exit barrier for the client may tempt the vendor to exhibit opportunism in the form of cost escalation, unreasonably high charges for services not explicitly mentioned in the contract, assigning inexperienced staff to the project, reduced quality and service levels, or holding the client captive to obsolete or inappropriate technologies.

Measurement difficulty translates into inscrutability of the vendor's work processes. Since both short-termand long-term contracts are much more conducive to the measurement of outcomes rather than processes, the vendor's internal practices remain largely hidden from the client. This may trigger not just opportunism of the kind discussed previously, but also vendor manipulation of internal project management data, to deflect culpability in problem situations. Finally, uncertainty refers to the prospect of unanticipated developments in the technological, business, or political environments, which are of particular concern, given the global nature of offshoring relationships.

Client organizations are aware of these pitfalls. In efforts to preempt problems that might stem from asset specificity, dependence, measurement difficulty, and uncertainty, some attempt to anticipate as many contingencies as possible, and to incorporate them into intricate contracts. However, the preemptive use of contingent contractual clauses is a futile exercise. With consultants and legal experts in tow, such organizations can eventually get to the point where the sheer overheads of administering these contracts make them untenable. Alternatively, the mistrust engendered by minutiae can vitiate their relationships with offshore vendors. The intensification of these dysfunctional dynamics provides a window for network-style relationships to replace contracts.

\section{Stage 2: Networks}

As application complexity increases, the efficacy of contractual mechanisms breaks down. The client's success with unstructured, intricate projects is more dependent on the vendor's internal practices and methods than before. This creates the need for better scrutiny of the vendor's processes that contracts alone are unable to provide, given their enforcement-oriented nature. Higher-task complexity necessitates joint coordination and a closer, more cooperative working relationship. Pronounced differences in location, culture, business processes, and regulatory practices stemming from the very nature of offshoring magnify these imperatives. A network-like linkage based on trust, solidarity, shared values, and open communication therefore represents a better option for the client because it engenders procedural coordination, vendor self-enforcement, and reciprocity (collaboration and cooperation). The establishment of such a relationship also tends to 
foster product and process innovation (Ritter \& Gemunden, 2003).

Interorganizational networks, such as joint ventures, alliances, associations, and consortia, typically consist of three or more organizations. However, a client-vendor dyad with soft interorganizational boundaries can exhibit working interfaces and other properties similar to those of classic networks. The major advantage of network-like relationships over purely contractual mechanisms for offshored development work would be an enhanced facilitation of the codification and communication of technological skills and organizational knowledge (Park, 1996). In particular, underlying, tacit knowledge is more successfully exchanged due to the mutual trust, strong social ties, and shared values/systems in such relationships. This has been confirmed both in the IT domain (Pardo, Cresswell, Thompson, \& Zhang, 2006), as well as in general (Dhanaraj, Lyles, Steensma, \& Tihanyi, 2004). For IT projects, the process of knowledge integration among collaborating organizations is also facilitated by social relationships and social capital (Bhandar, Pan, \& Tan, 2007). The successful codification and transfer of tacit, undocumented knowledge is crucial for more complex applications, as it provides the offshore vendor a better grasp of the client's general business context and unstructured aspects of task requirements. Although such knowledge exchanges increase coordination costs even more (Sobrero \& Roberts, 2001), they are accompanied by the joint creation of new knowledge, a higher order benefit (Sharma, 1997). Both tacit knowledge transfer and new knowledge creation are invaluable in the development of more complex applications, and necessary for synergistic innovations to emerge (Hardy, Phillips, \& Lawrence, 2003).

Procedural coordination, a key attribute of network-style relationships, enhances the effectiveness of existing contractual client-vendor exchanges when used as a secondary linkage mechanism (Sobrero \& Schrader, 1998). The complementary advantages it provides are highly effective, even if the original contractual exchanges were highly customized (Poppo \& Zenger, 2002). Studies of IT outsourcing have shown that trust, another critical attribute of networks, is preferred over contracts, particularly when contractual hazards are perceived as high (Barthelemy, 2003). In an empirical study, IT outsourcing projects were found to often begin with simple, outcome-oriented controls in place, but performance problems usually led to the introduction of additional controls oriented towards trust, vendor behavior, and clan-like affiliation (Choudhury \& Sabherwal, 2003). Another empirical study, focused on software offshoring by small firms, found that clients attempted to mitigate the high inherent transaction costs of contracts through embedded network ties in the form of mutually trusted individuals or "liaisons of knowledgeflows" (Carmel \& Nicholson, 2005). The importance of trust in interorganizational collaboration is well documented elsewhere too, both for IT outsourcing (e.g., Jennex \& Adelakun, 2003; Lanfield-Smith \& Smith, 2003; Sabherwal, 1999; Willcocks \& Choi, 1995) and in general (e.g., Vangen \& Huxham, 2003; Zaheer, McEvily, \& Perrone, 1998).

\section{Stage 3: Hierarchies}

The introduction of trust and clan-like affiliation represents a step up from an exclusive reliance on contracts. However, network-style client-vendor relationships, by themselves, or in conjunction with long-term contracts, by no means represent the stable state. The very network attributes that serve to bring the client and vendor together in a closer working relationship, that is, trust, reciprocity, effective knowledge transfer, and vendor self-enforcement, ultimately render it ineffective. Eventually, more authoritative mechanisms are needed, and the appropriate relationship is a command-oriented hierarchy. This may be achieved in one of two ways. The first entails the client 
acquiring a formal stake in a vendor organization through part- or full- ownership, that is, vertical integration. In the second approach, the client sets up a captive offshore subsidiary of its own (Preston, 2004).

Neither of these two culminating stages may be feasible for every client organization. Contextual attributes often play large roles in decisions to strengthen or relinquish control of interorganizational activities. For example, a study of IS outsourcing in city governments found that a variety of political, budgetary, and human resource factors, unique to these institutions, influenced their decision-makers to actually increase the amount of contractual outsourcing relative to work undertaken in-house or otherwise controlled tightly, given conditions of asset specificity and uncertainty (Miranda \& Kim, 2006). In another instance, a study of interorganizational $R \& D$ relationships reported that it would be in the interests of clients that were currently in relational exchanges with vendors to lapse into formal contractual modes, under conditions of increased ambiguity, but without concomitant increases in volatility (Carson, Madhok, \& Wu, 2006). Notwithstanding such contingent and contrarian contexts, the following discussion justifies the eventual need for authoritative mechanisms, under more general and typical conditions.

The primary impetus for the transition from Stage 2 to Stage 3 comes from continuing changes to the attributes of offshored applications, to the point where higher complexity will be increasingly accompanied by criticality to the client's business processes (Jensen, 2004). This is but a natural outcome of a close working relationship in which client-vendor synergies are constantly being explored. Business criticality poses enhanced risks, including the loss of core competencies to industry competitors (Hoecht \& Trott, 2006). It necessitates greater checks and balances on the vendor than are feasible through the network. Trust and reciprocity alone become insufficient to maintain a healthy relationship, and institu- tional control mechanisms are needed (Miles \& Snow, 1984). The resulting swing towards monitoring and formalization, however, threatens the autonomy of the partner organizations, even as they are highly interdependent (Van de Ven \& Walker, 1984). The implementation of new checks, balances, and controls also imposes even higher coordination costs, which destabilize and ultimately break the network (Park, 1996). Thus, networks, like contractual markets in the previous stage, eventually unravel in the face of ever-changing attributes of offshored applications. Key empirical evidence for this comes from a study that found that partner commitment in outsourcing relationships actually declines with the age of the relationship, increasing the chances of conflict (Lee \& Kim, 1999).

Trust, a fundamental basis of network-like arrangements, is known to be particularly fleeting in knowledge-sharing relationships. The progression of such relationships is more importantly affected by procedural justice than by trust (Daellenbach \& Davenport, 2004), and by structures that propagate goal congruence, particularly in the presence of opportunism (Jap \& Anderson, 2003). In a study, opportunism was found to be reduced more by formalizing policy than by encouraging cooperation (Dahlstrom \& Nygaard, 1999). Procedural justice, goal congruence, and formalization are all attributes associated more closely with hierarchical relationships than networks.

In a seminal research study, equity-based mechanisms (e.g., part or full ownership of one organization by the other, etc.) were found to benefit partner organizations in a relationship more than non-equity mechanisms (Zollo, Reuer, \& Singh, 2002). Likewise, in a study of strategic alliances, equity-based alliances were found to promote greater inter-firm knowledge transfer (Mowery, Oxley, \& Silverman, 1996). As has been noted, application development offshoring entails a high degree of knowledge sharing and transfer. A study of vertical partnerships found that linkages that support the extensive integration of the 
structures and management of both organizations were more successful from the perspectives of both parties (Donada, 2002). Another study, focusing on asymmetric partnerships in particular, found that effectiveness and competitive advantage were higher when the leader organization utilized authoritative coordination mechanisms (Hernandez-Espallardo \& Arcas-Lario, 2003).

In other evidence, transaction cost economics theory (Williamson 1975, 1985) predicts that a preponderance of transactions, in which assets utilized have relatively little value outside of the transaction (high asset specificity), will lead to an integration of assets. The firm that stands the most to lose from a hold-up (i.e., the client) by the other firm will tend to want to acquire the assets of the other. It has also been shown that in an interorganizational relationship where the two firms hold complementary assets, the sum total of these assets lead to synergies or increasing returns to scale, and therefore, there is a natural tendency for integration, or, for both sets of assets to be acquired by one firm (Hart, 1995).

Last, but not least, the introduction of a hierarchy alleviates internal political concerns in the client organization regarding loss of valued in-house technical expertise and skills to offshore vendors. The establishment of a hierarchy brings these skills back into the client's fold and under its control, albeit possibly at arms length. This regained expertise may now be leveraged by the client and sold to other organizations, thus providing an added source of business revenue.

\section{Depicting These Stages as Trade-Offs Between Coordination Costs and Vendor Control}

From the client's perspective, a visual explanation for the evolution through the three stages may be provided by mapping each stage on a two-dimensional graph, using coordination costs incurred and vendor control achieved as the perpendicular axes (Figure 1). Most client organizations initiate offshore applications development in hopes of reduced development costs. Lack of prior experience with offshore vendors leads them to select wellstructured applications of low complexity at this exploratory stage. This translates into the need for a simple relationship characterized by low coordination costs and little need to control the vendor's internal processes. Contractual markets best fit these modest circumstances. Repeated small successes may encourage the client to increase the frequency and complexity of offshored work, and pursue longer-term contracts, but markets in general remain the most efficient and effective relationship mechanism. Coordination costs may rise somewhat with the need to enforce various contractual bells and whistles, but the need for monitoring vendor processes remains low, given the outcome-measurement nature of contracts. In the Figure, therefore, Stage 1 (Contracts) is placed in the Low-Low quadrant.

With increasing complexity of knowledge-intensive work entrusted to the vendor, constraints such as asset specificity, asymmetry, measurement difficulty, and opportunism kick in. The client attempts to counter these by exerting greater influence on the vendor, through co-optation and closer working relationships, but with a concomitant rise in coordination costs. The additional resources expended by the client in an attempt to exercise influence, however, do not always translate into successful vendor control. This is because the vendor essentially represents an autonomous organization, despite the new closer working relationship with the client. The fundamental dilemma of a network is that while higher coordination costs are a given, the corresponding control achieved may or may not be greater, depending on the effectiveness of the informal dynamics in the network. In other words, the client's influence or control over the vendor's actions, processes, and outcomes may vary greatly. This uncertainty makes the network unsuited as a steady state relationship mechanism, should the client wish to entrust high-end, business-critical 
jobs to the vendor. Stage 2 (Networks) is therefore depicted in the center relative to the horizontal (coordination costs) axis, but spans a large part of the vertical (vendor control) axis.

Both success and failure with the network approach create a common result, the client's desire to wield greater control over the vendor. Success breeds the alluring prospect of higher-order, strategic benefits to be enjoyed by leveraging the vendor for even more complex work. And, unlike with projects of low complexity, network failure with moderately complex work presents the prospect of a sunken investment, something that the client wishes to prevent, again by tightening linkages with the vendor. Both outcomes, therefore, lead the client to seek greater formal control, and the informal network thus tends to evolve to a formal hierarchy. As the Figure shows, Stage 3 (Hierarchies) falls in the High-High quadrant, where the client incurs the high costs of vertical integration as a trade-off for reduced risk in terms of ability to control the vendor.

\section{OFFSHORE DEVELOPMENT FOR ETRUS: A CASE STUDY}

This section provides an illustration of the proposed evolutionary framework for offshored applications development, in the form of a case study. The narrative describes how the interactions of a real-world client organization with various offshore development vendors have successively mirrored the three stages of contracts, networks, and hierarchies. It highlights the interplay among various factors influencing this evolution, including constantly changing objectives, internal imperatives, and external compulsions on both sides. While the specific circumstances of this case are unique, the broader lessons it offers are consistent with the proposed evolutionary framework. In order to maintain confidentiality yet preserve the essence of the case, the identities of the client and key vendor organizations have been disguised, and other descriptive statistics and facts carefully distorted.

Figure 1. Coordination costs vs. vendor control: A trade-off

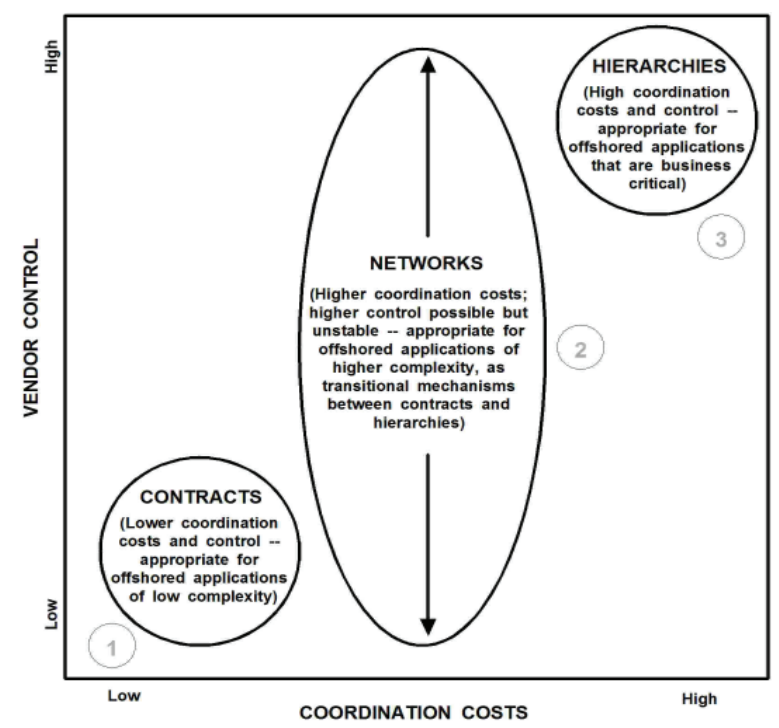


Etrus Corp. is a 13-year-old specialty telecommunications company whose expertise lies in identifying and relieving critical stress points and bottlenecks that impede its business customers' network performance. Using a mix of systems, software, and services, it helps its customers make maximum use of their applications that drive their businesses, while minimizing the total cost of their network ownership. Originally established as a "Delaware Corporation" in the high-end IP-based optical niche market, the company has since grown tremendously to approximately $\$ 400$ million in annual sales, largely through a series of acquisitions and mergers, including 11 in the past 8 years. It has also carefully crafted technology and business partnerships with major telecom players, such as Cisco, in order to offer a fuller range of solutions for its customers. Comprising of 1,500 employees, it now occupies specific niches across the breadth of telecommunications and serves customers on every major continent. These include cable service providers, telecommunications companies ("telcos"), such as Verizon, British Telecom, MCI, and AT\&T, government agencies, and private corporations with their own networks. Its products and services include multiplexers, aggregators, switches, integrated platforms/systems, and specialized network layer services/enhancements, some of which have won prestigious industry awards. Essentially a design and engineering firm, Etrus envisions and builds new off-the-shelf products for both the horizontal and vertical market, with customized variations for individual customers. Its contemporary rivals include Cisco, its business partner, as well as Lucent and Nortel. Along the way, Etrus has also acquired ISO 9001 certification.

Etrus' foray into applications development offshoring began with two conversion-oriented projects. These were precipitated by Etrus' series of acquisitions of other specialty telecommunications companies about three years ago. The new product development processes of both Etrus and the acquired companies had depended extensively on an industry standard product-management software tool from Agile that enabled them to manage the cost of their products and to track various aspects of their supply chain, for example, tracking parts and materials for manufacturing. While this platform compatibility between the acquiring and acquired companies was definitely a positive feature, these companies were all using different versions of the Agile software, and therefore, essentially employing somewhat different design, documentation, and manufacturing standards. Thus, an important objective was to get the data of the acquired companies into the structure and standards followed by Etrus, so that the consolidated data could be managed centrally in an integrated manner. One of the conversion projects, therefore, entailed upgrading the software used by an acquired partner to a more modern and recent version, by converting its design and database structure and content to be compatible with that used by Etrus. The other project actually entailed rolling a more recent version back to an older version, in the case of a different acquired partner who was using a more modern version of the software than Etrus. While these conversion tasks were highly structured and fairly straightforward, they could not be fully automated, as the conversion process consisted of some decision points, choices, and new data creation. In addition, as Etrus had decided to leverage the opportunity created by both conversion efforts by adding new functionality to the off-the-shelf product, this called for some custom programming.

Both conversion projects were outsourced to a Silicon Valley based vendor called Blue Ridge, which has technology and business relationships with Agile, and which entrusted the projects to its offshore subsidiary in India. Etrus' selection of Blue Ridge was based on the latter's expertise with Agile software, and on its apparent application development process maturity. This maturity was evidenced by its ISO-9001 certification, and its achievements related to the Software Capability Maturity Model (SW-CMM), developed by 
Carnegie-Mellon University's Software Engineering Institute (SEI). While the principles of SWCMM continue to be followed by organizations worldwide, the model itself has been superseded by a newer one called Capability Maturity Model Integration (CMMI), also from SEI. The original SW-CMM focused on software development processes. Its structure was characterized by five levels of increasing maturity that were Level 1-Initial, Level 2-Repeatable, Level 3-Defined, Level 4-Managed, and Level 5-Optimizing. Organizations at Level 5 epitomize highly mature, efficient, productive, innovative, and proactive development processes. Blue Ridge used a proprietary extended framework that focused on key processes, and its unique internal governance mechanisms periodically monitored ongoing projects to provide directional guidance as well as issue resolution. It had previously successfully employed its skills and methodology with Fortune 100 customers, and prided itself on being able to provide clients with total visibility of up-to-theminute performance metrics and execution status of ongoing projects.

Blue Ridge completed each project in about 4 weeks at a cost of approximately $\$ 20,000$. Both development projects were deemed to be resounding successes. In the words of Etrus' VP of Engineering Services, the conversion work, together with the custom built features from Blue Ridge "dramatically reduces the time to take a product from design to large-scale production, giving Etrus vastly more revenue and market share. This enables us to achieve aggressive new product launch objectives through supply chain collaboration, so critical to our success. We couldn't have asked for better support from Blue Ridge."

These initial small experiments with application development offshoring represented the first offshoring stage for Etrus. The successful culmination of contracts with Blue Ridge set a positive internal tone within Etrus, and bolstered the confidence of its IT managers in offshored development. As the company continued to grow rapidly through acquisitions, the IT group decided that it would be best to focus in-house resources on tasks associated with new product development, and offshore more of the other routine application development work. However, the fast pace of corporate change and the quick adaptation expected from IT meant that the internal IT staff had very little time available to engage collaboratively with vendors to jointly generate specifications that were clear and detailed enough for the latter to take over and complete the development process. This constraint prevented many new offshoring projects from being initiated in the first place. The solution that was agreed upon was to look for "parcels" of work that were both complex enough to leverage the cost and quality benefits of offshored development, and at the same time, structured enough to not set the internal IT group back in terms of time spent working with the vendor to generate excessively detailed specifications. This approach would also require the careful selection of vendors whose strengths matched up to the attributes of specific projects. The first such opportunity came about in the shape of a need to customize and implement an internal business application, an off-the-shelfengineering and design information system oriented around engineering resources and portfolio management, built on a popular technology platform. The rest of the Etrus case study describes the characteristics of this particular development project, how the offshore vendor was selected and managed, the outcome of the development effort, and a discussion of its implications.

This project represented a moderately complex application whose deliverables consisted of the system setup, the standard template setup and custom template design, the standard reports setup and custom report design, and some custom workflow programming logic. It entailed a different technological platform than the other two projects, and Blue Ridge was deemed not to possess the ideal expertise for this job. Consistent with the 
aforementioned need to carefully select a vendor whose strengths matched up with the attributes of the application to be developed, the project was instead awarded directly to Fiore, a leading offshore-based global IT firm. Fiore's strengths range across the full technology-life-cycle spectrum, including business and technology consulting, research and development, implementation, and process ownership/operations. For its applications development business line, Fiore owns and operates sophisticated, mature offshore development facilities. Aside from Fiore's excellent reputation, Etrus had had prior contacts with Fiore's R\&D group, who had designed and developed some components of their standard product offerings in the past. As Fiore was well placed in the high-end, engineering software niche, Etrus' IT managers believed that Fiore possessed the background and skills to successfully deliver this application, which was more complex relative to the first two that they had offshored earlier.

The application, when complete, would provide Etrus with the resource loading and skill prediction requirements across their entire engineering portfolio. It would enable them to load up all their engineering projects that they had in the pipeline, track their status, their project plans, and the skills that it was going to take to get them done. This project portfolio information could then be rolled up and mapped onto the skills sets of individual product designers and engineers, to yield accurate estimates of how many people of each skill set they would need over the next couple of years, and the personnel budgets that all of this would entail. It would also enable Etrus to build the background or foundation to support the product development commitments that their sales people were making to their customers, and to reconcile market realities with their planning processes.

At a higher level of complexity relative to the prior offshored development projects, the development of this application called for closer communication and interaction between client and offshore vendor. However, even as this project was underway, Etrus' internal resources, including IT, were under severe strain due to other pending corporate acquisitions. It was decided, therefore, to focus as much of the iterative dialog with the vendor as possible in the initial stages of the development life cycle, and to then hand over the process entirely for Fiore to manage, up until the end product was ready. Fiore's project leads, who were technical specialists, worked closely with Etrus' internal IT staff in the initial stages. This minimized the number of contact points between client and vendor in the later stages of development, thereby enabling Etrus to function within their time constraints, but also ensuring that each contact point served as an intensive knowledge transfer linkage. Once the leads had internalized the specifications and the deliverables, the client would then be ready for them to move the actual development work offshore to Fiore's premises, and to manage it from there.

Thus, in the requirements analysis stage, Etrus' internal IT staff not only provided the vendor with documents containing detailed requirements specifications, but also some graphical mock-ups of key deliverables such as input/output screens and reports. These prototypical screens and reports were then subjected to iterative changes based on short, rapid feedback cycles between Fiore and Etrus. While the technical context was well documented and communicated to the vendor in this manner, the transfer of business-domain knowledge or the organizational context, that is, knowledge of the client's business processes, was not given as much attention. Both clientand vendor agreed that the application, while moderately complex in effort, represented a fairly structured task with few unknowns, for instance, the hardware, software, and the technical architecture for the project had already been decided by Etrus. And, aside from some examples of how "things were done" at Etrus, it was not really necessary to get into details of the business knowledge in order for Fiore to complete the project, despite the fact that the two organizations had no prior interactions. 
This was also the reason why the project leads from Fiore were technical specialists rather than business or process specialists.

Since the moderate level of application complexity also called for some degree of vendor control, Etrus chose to anchor this control to outcome-oriented measurable standards for the vendor to follow. This was consistent with the fact that the technical architecture had already been set by the client. The contract therefore spelled out both timelines and quality standards. An example of the latter was specifications pertaining to the expected number of rework cycles and other measures of operational efficiencies, such as software bugs. These standards were based on Etrus' objective assessment of the project's complexity, and its own historical data from other internally developed applications. Also added to the contract were specific deliverables associated with checkpoints. One example of a deliverable at a checkpoint would entail running the set of custom workflows through a series of test processes to ensure that the set touched all the right spots in the workflow.

Enforcement of standards, while not strictly followed through formal audits, was built into these checkpoints as threshold gates. If deliverables were determined not to have met certain standard levels, exit clauses would kick in, enabling Etrus to revisit the contract or to stop the project altogether. Essentially, the client could then choose to take all the work that had been done to date, together with documentation, and to finish the project themselves, or hand it over to another vendor. Fiore would then be paid for work done to that point and no further. The intent of these clauses, though, was not based on an adversarial premise, they were placed in the contract largely as mechanisms to document the expectations of quality that both client and vendor were committed to, essentially, as vendor guidelines. Further, although the contract focused on deliverables rather than process, it did not contain any provisions for special rewards or incentives for work that exceeded standards or was completed ahead of schedule. The message to Fiore was, "We don't have the time to accomplish this ourselves, so as long as you can manage the project and demonstrate the deliverables and the milestones, we'll be perfectly happy."

While the client, due to various reasons, including time constraints and the nature of the development work, maintained a clearly outcomeoriented stance, the vendor, on the other hand, was CMM-certified at a high level, and took pride in following strictly established, documented, and publicized processes. Despite the fact that Fiore was a big player for whom this project represented, at best, a small foot in the door, it proceeded to apply high process standards for itself, including rigorous testing and documentation. This was over and above its self-enforcement of the deliverable-oriented contractual terms that had been set by Etrus. These respective outcome- and process-oriented approaches of client and vendor had a decidedly synergistic effect; the end result was a development project that came in at only slightly higher than the funds budgeted $(\$ 45,000$ vs. $\$ 41,000)$, took less time than expected (6 weeks vs. 2 months), and that was regarded as successful by the client, despite an unplanned switch of offshore project managers in the middle of the development effort. The vendor's process orientation ensured the continuity that was needed at the point of this switch, and the carefully crafted deliverables-oriented measures that had been set by Etrus helped Fiore carve the path to an unambiguous end point. When the project was complete, the in-house IT staff at Etrus was unanimous in its opinion that although the work could have been done internally, it would have been more unpredictable, entailed a longer learning curve, cost approximately $50 \%$ more, and probably would not have been of as high a technical quality.

Etrus' successful experience with Fiore represents the second stage in its evolutionary experiences with application-development offshoring. This stage was characterized by higher complexity 
work, a closer relationship with the vendor, and a greater focus on process. Ironically, though, as the IT staff at Etrus now considers a full-fledged role for offshored applications development, some of the key factors that worked to its advantage in its recent project are the ones that it thinks will work against it in the future. Specifically, the dynamics of the telecommunications industry are changing, and the acquisition and consolidation mania is beginning to slow down. This implies that the IT staff will be less engaged in putting out acquisition-related fires, and be more available to leverage offshoring by sending increasingly complex applications out for development. While the benefits of offshoring more complex applications are likely to be of a higher order, the need for ever-closer working relationships between client and vendor IT personnel is also expected to be greater. The higher the application complexity, the greater is the need for joint, iterative activities in any development effort. While the internal IT staff may finally have more time available for such collaborative client-vendor activities, the uncertainty embedded in complex applications usually also results in several rounds of changes to initial specifications, as possibilities are explored, knowledge is exchanged between client and vendor, and implications continually clarified. With vendors who flaunt high-level CMM certifications, this creates two problems. One has to do with the enormous level of detail needed in initially documented specifications, because CMM processes require extensive documentation. The second has to do with the communications, documentation, testing, and recertification costs of reworking these specifications with each round of changes. In other words, while vendor CMM certification provides reliability and confidence in the end product, it also adds a tremendous overhead burden to the cost structure. The net result can be that any incremental gains or values from initial offshoring work are offset by the high coordination costs of adhering to processoriented standards, such as CMM, as the work gets more complex.
For these reasons, Etrus has decided to disengage itself from Fiore. It has committed itself to establishing a captive (subsidiary) offshore application-development facility of its own in the near future, so that it can better leverage the higher-order benefits of offshoring and, at the same time, maintain some control over what would otherwise be exorbitantly high vendor coordination costs. Doing so will take Etrus into the third and final evolutionary stage for offshored development.

\section{DISCUSSION AND IMPLICATIONS}

Using a theoretical framework and a supporting case study, it has been argued that client-vendor relationships in offshored applications-development contexts evolve first from transaction-oriented, price-based contracts, to loose, informal, but fewer, networks based on trust and vendor self-enforcement. Subsequently, the growing complexity and criticality of applications introduces the need for greater checks and balances, and this necessitates a hierarchical arrangement, part- or full-client ownership of a vendor. While this final stage may not actually be feasible for every client, essentially, a cost-reduction game is replaced by one of risk control.

There is somewhat of an irony in the position taken by this chapter that a formal hierarchy ought to succeed a network-like stage in a client-vendor relationship. Vertical integration as a controloriented, preferred organizational response to external uncertainty was first proposed in a classic work a long time ago (Thompson, 1967). Many years later, however, it was argued that creating a hierarchy entails mechanisms considered unnecessary and overkill, difficult to establish, or too costly to sustain. In its place, the network, with its freedom of exit attributes, was then propounded as a superior response to dynamic, unpredictable environments (see for example: Achrol, 1997).

The knowledge of a natural progression can 
help decision makers on either side of an offshoring relationship. On the client side, senior business and technology executives can make more informed judgments regarding the viability of offshoring beyond the short term, given the kind of commitments that such vendor relationships will ultimately entail. The resultant better decision process will prevent organizations that are ill equipped to cope with the concomitant costs, from embarking upon offshoring complex or critical projects. It will also enable organizations that do possess such a capability, to be better prepared for the internal changes that will accompany changing relationship structures with vendor organizations. At the least, the clarity resulting from understanding the sequential stages of interorganizational processes will encourage executives to work up candid assessments of why they might be interested in offshoring in the first place.

On the vendor side, the implications of a relationship progression are perhaps more profound. With the realization that clients will seek to regain control as applications evolve to become complex and critical, decision makers in vendor organizations are faced with fundamental questions pertaining to organizational mission, culture, and employee work autonomy. For example, should they even let client-vendor relationships progress to such points, or plan to stay with lower- and mid-level work? The greatest dilemma here is for the creative, decentralized, organic types of offshore vendor organizations. On the one hand, they may value the empowerment that their internal environment provides them. On the other, this empowerment may be threatened when put to good use for higher-level work.

For researchers interested in pursuing the progression of offshoring relationships further, this chapter offers a couple of different directions for more rigorous empirical inquiry. The most obvious one is the implicit proposition that as a client-vendor offshoring relationship is established, ages, and matures, vendor oversight is first conducted through (possibly increasingly com- plicated) contractual mechanisms, then through loose, trust-based, affiliation-solidarity networks, and finally a client-controlled hierarchy. An alternative investigation scheme would avoid using relationship age as the progression benchmark, and instead look for evidence of the three stages by employing application complexity as a surrogate for relationship maturity. If either of these two methods reveals the existence of such stages, then the next logical step would be to test whether hierarchies as the interorganizational structure of choice in mature relationships are really more effective than other alternative mechanisms.

\section{REFERENCES}

Achrol, R.S. (1997). Changes in the theory of interorganizational relations in marketing: Toward a network paradigm. Journal of the Academy of Marketing Science, 25(1), 56-71.

Barringer, B. R., \& Harrison, J. S. (2000). Walking a tightrope: Creating value through interorganizational relationships. Journal of Management, 26(3), 367-403.

Barros, M. O., Werner, C. M. L., \& Travassos, G. H. (2004). Supporting risks in software project management. The Journal of Systems and Software, 20(1-2), 21-35.

Barthélemy, J. (2003). The hard and soft sides of IT outsourcing management. European Management Journal, 21(5), 539-548.

Barthélemy, J., \& Quélin, B. V. (2006). Complexity of outsourcing contracts and ex post transaction costs: An empirical investigation. The Journal of Management Studies, 43(8), 1775-1797.

Benamati, J., \& Rajkumar, T. M. (2002). The application development outsourcing decision: An application of the technology acceptance model. The Journal of Computer Information Systems, 42(4), 35-43. 
Bhandar, M., Pan, S. L., \& Tan, B. C. Y. (2007). Towards understanding the roles of social capital in knowledge integration: A case study of a collaborative IS project. Journal of the American Society for Information Science and Technology, 58(2), 263-274.

Carmel, E., \& Nicholson, B. (2005). Small firms and offshore software outsourcing: High transaction costs and their mitigation. Journal of Global Information Management, 13(3), 33-54.

Carson, S. J., Madhok, A., \& Wu. T. (2006). Uncertainty, opportunism, and governance: The effects of volatility and ambiguity on formal and relational contracting. Academic of Management Journal, 49(5), 1058-1077.

Cata, T., \& Raghavan, V. V. (2006). Lifecycle of outsourcing relationships: A case study investigation. Journal of Information Technology Case and Application Research, 8(3), 11-26.

Choudhury, V., \& Sabherwal, R. (2003). Portfolios of control in outsourced software development projects. Information Systems Research, 14(3), 291-314.

Clemons, E. K., Reddi, S. P., \& Row, M. C. (1993). The impact of information technology on the organization of economic activity: The "move to the middle" hypothesis. Journal of Management Information Systems, 10(2), 9-35.

Daellenbach, U. S., \& Davenport, S. J. (2004). Establishing trust during the formation of technology alliances. Journal of Technology Transfer, 29(2), 187-202.

Dahlstrom, R., \& Nygaard, A. (1999). An empirical investigation of ex post transaction costs in franchised distribution channels. Journal of Marketing Research, 36(2), 160-170.

Dhanaraj, C., Lyles, M. A., Steensma, H. K., \& Tihanyi, L. (2004). Managing tacit and explicit knowledge transfer in IJVs: The role of relational embeddedness and the impact on performance.
Journal of International Business Studies, 35(5), 428-442.

Donada, C. (2002). Generating cooperative gain in a vertical partnership: A supplier's perspective. Canadian Journal of Administrative Sciences, 19(2), 173-183.

Dyer, J. H., \& Singh, H. (1998). The relational view: Cooperative strategy and sources of interorganizational competitive advantage. Academy of Management Review, 23(4), 660-679.

Goes, J. B., \& Park, S. H. (1997). Interorganizational links and innovation: The case of hospital services. Academy of Management Journal, 40(3), 673-696.

Goo, J., Kishore, R., Nam, K., Rao, H. R., \& Song, Y. (2007). An investigation of factors that influence the duration of IT outsourcing relationships. Decision Support Systems, 42(4), 2107-2125.

Gottschalk, P., \& Solli-Sæther,H. (2006). Maturity model for IT outsourcing relationships. Industrial Management \& Data Systems, 106(2), 200-212.

Hardy, C., Phillips, N., \& Lawrence, T. B. (2003). Resources, knowledge and influence: The organizational effects of interorganizational collaboration. The Journal of Management Studies, 40(2), 321-347.

Hart, S. L. (1995). A natural-resource-based view of the firm. Academy of Management Review, 20(4), 986-1014.

Hernandez-Espallardo, M., \& Arcas-Lario, N. (2003). The effects of authoritative mechanisms of coordination on market orientation in asymmetrical channel partnerships. International Journal of Research in Marketing, 20(2), 133-152.

Hoecht, A., \& Trott, P. (2006). Outsourcing, information leakage and the risk of losing technology-based competencies. European Business Review, 18(5), 395-412. 
Jap, S. D., \& Anderson, E. (2003). Safeguarding interorganizational performance and continuity under ex post opportunism. Management Science, 49(12), 1684-1701.

Jennex, M. E., \& Adelakun, O. 2003. Success factors for offshore information system development. Journal of Information Technology Cases and Applications, 5(3), 12-31.

Jensen, B. K. (2004). The expert opinion. Journal of Information Technology Cases and Applications, 6(4), 51-54.

Khan, N., \& Fitzgerald, G. (2004). Dimensions of offshore outsourcing business models. Journal of Information Technology Cases and Applications, 6(3), 35-50.

King, W. (2005). Outsourcing becomes more complex. Information Systems Management, 22(2), 89-90.

Koh, C., Ang, S., \& Straub, D. W. (2004). IT outsourcing success: A psychological contract perspective. Information Systems Research, 15(4), 356-373.

Lanfield-Smith, K., \& Smith, D. (2003). Management control systems and trust in outsourcing relationships. Management Accounting Research, 14(3), 281-307.

Lee, J.-N., \& Kim, Y.-G. (1999). Effect of partnership quality on IS outsourcing success: Conceptual framework and empirical validation. Journal of Management Information Systems, 15(4), 29-61.

Lonsdale, C. (2001). Locked-in to supplier dominance: On the dangers of asset specificity for the outsourcing decision. The Journal of Supply Chain Management, 37(2), 22-27.

Lu, A., Koch, G., Folco, G., Dillon, B., Maceška, R., \& Gibin, E. (2007). Worldwide IT spending 2006-2010 forecast update by vertical market: North America, Western Europe, Asia/Pacific, and rest of world. International Data Corporation Document \#205018.

Matloff, N. (2004). Globalization and the American IT worker. Communications of the ACM, 47(11), 27-29.

Miles, R. E., \& Snow, C. C. (1984). Fit, failure and the hall of fame. California Management Review, 26(3), 10-28.

Miranda, S. M., \& Kim, Y.-M. (2006). Professional versus political contexts: Institutional mitigation and the transaction cost heuristic in information systems outsourcing, MIS Quarterly, 30(3), 725-753.

Mowery, D. C., Oxley, J. E., \& Silverman, B. S. (1996). Strategic alliances and interfirm knowledge transfer. Strategic Management Journal, 17(Winter Special Issue), 77-91.

Natovich, J. (2003). Vendor related risks in IT development: A chronology of an outsourced project failure. Technology Analysis \& Strategic Management, 15(4), 409-419.

Oza, N. V., Hall, T., Rainer, A., \& Grey, S. (2006). Trust in software outsourcing relationships: An empirical investigation of Indian software companies. Information and Software Technology, 48(5), 345-354.

Pardo, T. A., Cresswell, A. M. Thompson, F., \& Zhang, J. (2006). Knowledge sharing in crossboundary information system development in the public sector. Information Technology and Management, 7(4), 293-313.

Park, S. H. (1996). Managing an interorganizational network: A framework of the institutional mechanism for network control. Organization Studies, 17(5), 795-824.

Poppo, L. \&Zenger, T. (2002). Do formal contracts and relational governance function as substitutes or complements? Strategic Management Journal, 23(8), 707-725. 
Preston, S. (2004). Lost in migration: Offshore need not mean outsourced. Strategy \& Leadership, 32(6), 32-36.

Ramarapu, N., Parzinger, M. J., \& Lado, A. A. (1997). Issues in foreign outsourcing. Information Systems Management, 14(2), 27-31.

Richmond, W. B., \& Seidmann, A. (1993). Software development outsourcing contract: Structure and business value. Journal of Management Information Systems, 10(1), 57-72.

Ritter, T., \& Gemunden, H. G. (2003). Network competence: Its impact on innovation success and its antecedents. Journal of Business Research, 56(9), 745-755.

Sabherwal, R. (1999). The role of trust in outsourced IS development projects. Communications of the ACM, 42(2), 80-86.

Sharma, A. (1997). Professional as agent: Knowledge asymmetry in agency exchange. Academy of Management Review, 22(3), 758-798.

Sobrero, M., \& Roberts, E. B. (2001). The trade-off between efficiency and learning in interorganizational relationships for product development. Management Science, 47(4), 493-511.

Sobrero, M., \& Schrader, S. (1998). Structuring inter-firm relationships: A meta-analytic approach. Organization Studies, 19(4), 585-615.

The Software \& Information Industry Association. (2006). SIAA global software development survey report \# GBL-06, Special Study, December.

Tan, C., \& Sia, S. K. (2006). Managing flexibility in outsourcing. Journal of the Association for Information Systems, 7(4), 179-202.
Thompson, J. D. (1967). Organizations in action. New York: McGraw-Hill.

Van de Ven, A. H., \& Walker, G. (1984). The dynamics of interorganizational coordination. $A d$ ministrative Science Quarterly, 29(4), 598-621.

Vangen, S., \& Huxham, C. (2003). Nurturing collaborative relations: Building trust in interorganizational collaboration. The Journal of Applied Behavioral Science, 39(1), 5-31.

Whitten, D., \& Leidner, D. (2006). Bringing IT back: An analysis of the decision to backsource or switch vendors. Decision Sciences, 37(4), 605-621.

Willcocks, L., \& Choi, C. J. (1995). Cooperative partnership and "total" IT outsourcing: From contractual obligation to strategic alliance. European Management Journal, 13(1), 67-78.

Williamson, O. E. (1975). Markets and hierarchies: Analysis and antitrust implications. New York: Free Press.

Williamson, O. E. (1985). The economic institutions of capitalism. New York: Free Press.

Zaheer, A., McEvily, B., \& Perrone, V. (1998). Does trust matter? Exploring the effects of interorganizational and interpersonal trust on performance. Organization Science, 9(2), 141-159.

Zollo, M., Reuer, J. J., \& Singh, H. (2002). Interorganizational routines and performance in strategic alliances. Organization Science, 13(6), 701-713. 